\title{
Breeding biology of a relictual Maghreb Magpie (Pica mauritanica) population in Tunisia
}

\author{
Aymen Nefla ${ }^{1 *}$, Ridha Ouni $^{2}$, Slaheddine Selmi ${ }^{3}$ and Saïd Nouira ${ }^{1}$
}

\begin{abstract}
Background: The Maghreb Magpie (Pica mauritanica) is an endemic North African species. Available knowledge on this species is limited to historic descriptive data with no ecological information provided. Populations continue to dramatically decline in Tunisia, where only one relic population survives. Investigating the breeding biology of this species is essential for conservation purposes. The purpose of this study was to increase our understanding of the Tunisian relic population and provide detailed data on breeding biology over two breeding seasons (2017 and 2018).

Methods: This study occurred on a private farm of 650 ha, located $10 \mathrm{~km}$ from Dhorbania village at Kairouan Governorate, in central Tunisia. Active nests were monitored weekly during egg laying period and twice a week during hatching period. The Ivlev's electivity index was used to assess whether the frequency of use of nesting trees and bushes matched their availability in the study area. We recorded nest measurements and positions, and compared them using Wilcoxon signed-rank test. Variations of breeding parameters as number of eggs laid, hatchlings, and fledglings over years were performed using Mann-Whitney U-test and $x^{2}$ tests. We used a Generalized Linear Mixed Model (GLMM) to investigate how egg volume varied with clutch size and laying date.
\end{abstract}

Results: We investigated clutch size, egg size, hatching and fledging success, and evaluated how these parameters varied according to laying date and nest characteristics. Clutch size averaged $5.00 \pm 0.19$ but was significantly greater in 2017. Hatching success was $2.78 \pm 0.34$ eggs hatched per nest and fledging success reached $1.69 \pm 0.30$ young/ nest. Causes of nest failure included the depredation of nestlings by shrikes, cobras and rats (e.g. Lanius meridionalis, Naja haje and Rattus rattus), death of parents by the Black-shouldered Kite (Elanus caeruleus) and nest parasitism by the Great Spotted Cuckoo (Clamator glandarius). Clutch size, brood size and fledgling success were unaffected by laying date, nest volume and nest elevation. Egg volume decreased with laying date but was unaffected by clutch.

Conclusion: Our study provides the first and only detailed data on reproductive parameters of the Maghreb Magpie in its entire geographic range (North Africa). Information gleaned from this study provides valuable information for monitoring and long-term conservation plans of the endangered Tunisian Magpie population. Additionally, our data provide an avenue of large-scale comparative studies of the reproductive ecology of the magpie complex.

Keywords: Clutch size, Laying date, Maghreb Magpie, Nesting habitat, Nest success, Relic population, Tunisia

*Correspondence: aymennefla2007@yahoo.fr

1 Department of Biology, Faculty of Sciences of Tunis, University of Tunis El Manar, El Manar II, 2092 Tunis, Tunisia

Full list of author information is available at the end of the article

\section{Background}

Investigating the breeding biology of bird species is an essential step for understanding their population dynamics and for focusing on conservation efforts. This is particularly important for poorly known species, especially those showing signs of declining populations.

The Eurasian Magpie (Pica pica) is a common bird species in the Palearctic area. Until recently, the North 
African population of this species was considered as a subspecies (Pica pica mauritanica). However, Ebels (2003) highlighted morphological and acoustic differences between the Maghreb population and those of Europe. Later, taxonomic and phylogenetic studies (Kryukov et al. 2017; Song et al. 2018) illustrated that the North African clade is the most divergent compared to other lines. Consequently the mauritanica subspecies is now considered as a separate species, the Maghreb Magpie (Pica mauritanica), endemic to North Africa (del Hoyo et al. 2018).

At the beginning of the twentieth century, the Maghreb Magpie was locally widespread in North Africa. In the past century, 12 isolated local populations were recorded in Tunisia (Lavauden 1924; Heim de Balzac and Mayaud 1962; Etchécopar and Hue 1964; Isenmann et al. 2005), 16 in Algeria (Etchécopar and Hue 1964; Isenmann and Moali 2000) and approximately 30 in Morocco (Etchécopar and Hue 1964; Thévenot et al. 2003; Bergier et al. 2017). Nowadays, the distribution of this species in North Africa is more fragmented and limited. For instance, only one relic population still survives in Tunisia, at the Sbikha region (Kairouan Governorate) (Ouni et al. 2018; Nefla et al. 2020). However, despite this critical situation and the urgency of adequate conservation measures, the ecology and dynamics of this relic population remain poorly understood due to the lack of detailed studies. Indeed, available knowledge on this species is limited to old descriptive data on its morphology and distribution (Lavauden 1924; Heim de Balzac and Mayaud 1962; Etchécopar and Hue 1964; Isenmann et al. 2005).

The breeding biology of the Eurasian Magpie has been well studied throughout its whole geographic range, particularly in the Palearctic region (Sachteleben et al. 1992; Eguchi 1995; Jerzak 1995; Dolenec 2000; Soler et al. 2001; Antonov and Atanasova 2003; Ponz and Gil-Delgado 2004; Tucakov and Kucsera 2008; Wang et al. 2008). Overall, these studies showed that egg laying generally occurs from mid-March to mid-April. They also showed that clutch size varied among populations, with an average value ranging from five to six eggs per nest, but fledging success was always less than two fledglings per nest. However, detailed data on the breeding parameters of the endemic Maghreb Magpie are still lacking.

The objective of this study was to increase our understanding of the ecology of this relic population and provide detailed data on its breeding biology over two consecutive breeding seasons. Specifically, we aimed to: (1) describe nesting sites and nest characteristics; (2) determine key breeding parameters, notably clutch size, egg volume, hatching success and fledging success, and; (3) investigate how these parameters varied according to laying date. We expected clutch size, egg volume and chick survival to decrease with laying date, in line with the general trend known in birds (Bengtson 1972; Parsons 1972; Newton and Campbell 1975; Hill 1984; Sedinger 1992; Christians 2002; Verhulst and Nilsson 2008). This trend is more likely to occur in our arid study area because food availability deteriorates rapidly as the breeding season progresses. Moreover, we expected that breeding success would be strongly related to nest position, especially nest elevation, as this parameter is supposed to influence nest conspicuousness and accessibility to predators.

\section{Methods \\ Study area}

The relic population inhabits a private, 650 ha, farm located $10 \mathrm{~km}$ from Dhorbania village $\left(35^{\circ} 58^{\prime} 16^{\prime \prime} \mathrm{N}-10^{\circ}\right.$ $01^{\prime} 15^{\prime \prime}$ E) at Kairouan Governorate, in central Tunisia (Fig. 1). The climate is semi-arid with annual rainfall of $290 \mathrm{~mm}$ and an average summer (June, July and August) temperature of $38{ }^{\circ} \mathrm{C}$ (Mougou et al. 2011). The farm comprises a mixture of cultivated land, including 150 ha of fruit trees and 50 ha of vegetable crops, and pasture area (450 ha) covered with bushy vegetation, including Sumac (Searsia tripartita) (76.5\% of cover), African Wolfbane (Periploca angustifolia) (10.5\%), Deciduous Shrub (Ziziphus lotus) (9\%), Ephedra (Ephedra sp.) (2\%) and European Boxthorn (Lycium europaeum) (1\%). Other trees [European Olive (Olea europaea), Almond (Prunus dulcis), Pistachio (Pistacia vera), Atlas Mastic Tree (Pistacia atlantica), Wild Olive (Olea oleaster), Cyclops Wattle (Acacia cyclops) and Cape Gum (Acacia horrida)] comprised $1 \%$ of coverage. We also recorded White Wormwood (Artemisia herba alba), Rosemary (Rosmarinus officinalis), Conehead Thyme (Thymus capitatus), Crown Friar (Globularia alypum), White Horehound (Marrubium vulgare), Esparrago (Asparagus alba) and Needle Grass (Stipa tenacissima).

\section{Nest monitoring}

From March to late June in 2017 and 2018, we visited the study site to locate nests of breeding magpies. Located nests were visited weekly during the egg laying period (in order to minimize disturbance) and twice a week during hatching until 25 days post-hatch. All active and unoccupied nests were geo-referenced using GPS (Garmin Etrex 75049).

In 2017, we recorded the height $(\mathrm{m})$, diameter $(\mathrm{m})$ and tree species the nest was in. For each nest, we also recorded nest elevation (ground to nest distance) $(\mathrm{m})$ and nest to tree top distance (m). Nest volume (in liters) was also calculated as: $V=(4 / 3) \times\left(\pi \times a \times b^{2}\right) / 1000$, where $a$ 


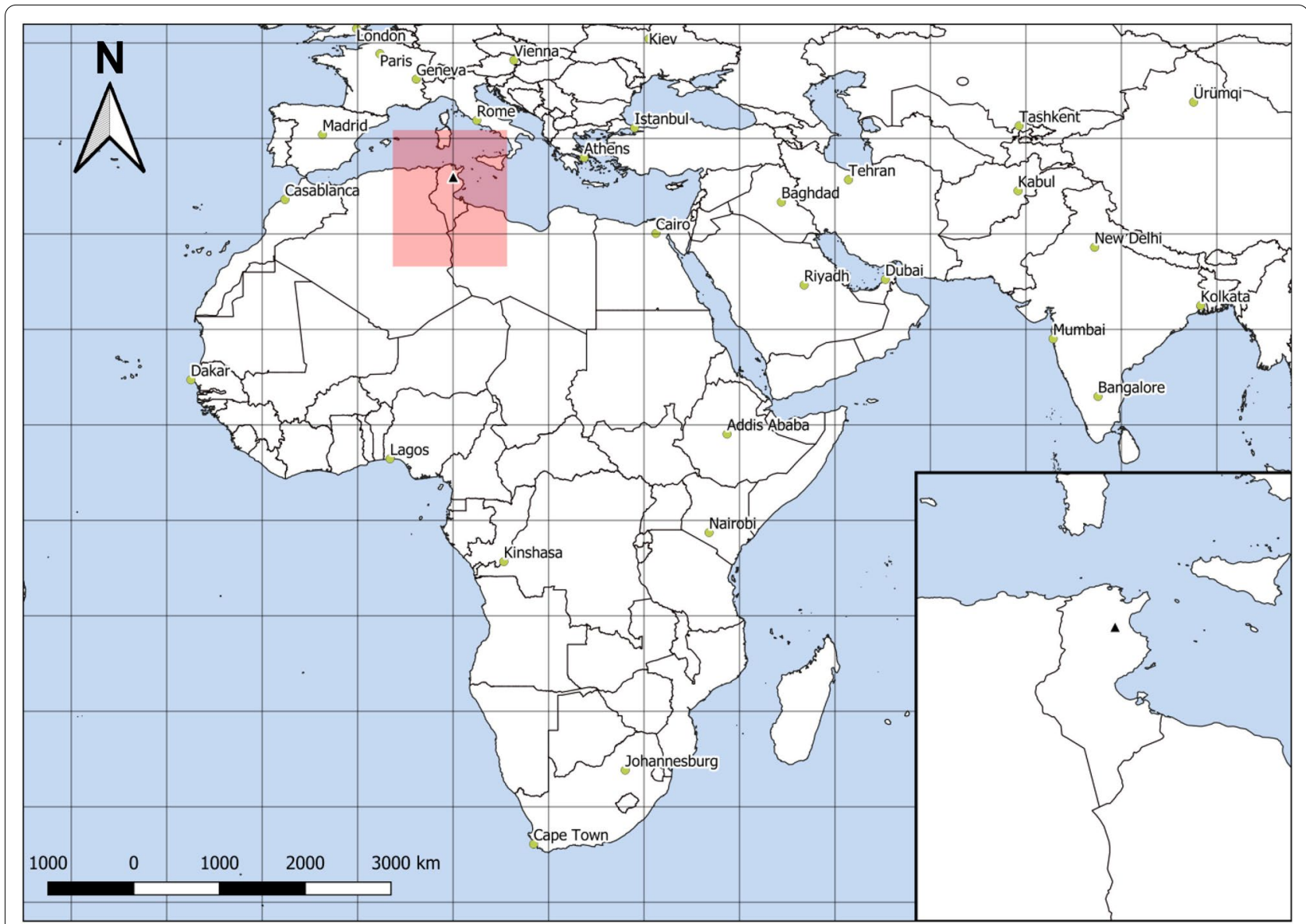

Fig. 1 Map showing the Maghreb Magpie breeding area in Tunisia (black triangle)

is the largest radius of the ellipsoid nest $(\mathrm{cm})$ and $b$ half nest width (cm) (Soler et al. 1995).

\section{Reproductive data collection}

We used an endoscopic camera to check nest contents. For each nest we recorded the date when the first egg was laid, the number of eggs in each nest (i.e. clutch size) and the number of nestlings that survived to 25 days posthatch (age at which nestlings scrambling made further visits impractical); we considered 25 days post-hatching as our operational criterion for fledging. The clutch was considered complete when there were no additional eggs after two consecutive visits. We considered a nest unsuccessful if it was found empty before the estimated hatching/fledging date or with damaged eggs/nestlings, since the incubation period was estimated to 15 days (Ouni 2018). We identified predators based on the nest condition and evidence in the nest. For example, rats typically leave eggshell fragments, while snakes feed on nests without leaving a trace (Pietz and Granfors 2000; Klug et al. 2010). In 2018, we used vernier calipers to measure
$( \pm 0.01 \mathrm{~mm})$ maximum length $(L)$ and breadth $(B ; \mathrm{mm})$ of 35 eggs from seven clutches. We calculated egg volume $\left(\mathrm{mm}^{3}\right)$ following Hoyt (1979): $V=0.51 \times L \times B^{2}$.

\section{Data analyses}

We assessed whether the frequency of use of nesting trees and bushes matched their availability in the study area, using the Ivlev's electivity index: $E=\left(r_{i}-p_{i}\right) /\left(r_{i}+p_{i}\right)$, where $r_{i}$ is the relative abundance of the tree/shrub species $i$ in the subset of trees/bushes used as nesting supports, while $p_{i}$ denotes the relative abundance of this tree/shrub species in the study area (Ivlev 1961). Values of $E$ range from -1 to +1 , with negative values indicating avoidance, positive values suggesting active selection, and values close to zero indicating random use. Moreover, as an investigation of nest position within the nest tree, we compared nest elevation to nest distance from tree top using the Wilcoxon signed-rank test.

We used data collected at active nests (during the two breeding seasons of 2017 and 2018), to determine clutch size (number of eggs laid), hatching success (number of 
eggs hatched), and fledging success (number of fledglings produced). We assessed whether these parameters varied between the two years of study using Mann-Whitney $U$-test. Moreover, a series of colony-level parameters were also determined: egg hatching rate (total number of eggs hatched/total number of eggs laid in the colony), nestling survival rate (total number of fledglings/total number of eggs hatched) and breeding success (number of fledglings/number of eggs laid). We also calculated nest survival (number of nests with at least one hatched egg/total number of nests), fledging survival (number of nests raising at least one fledgling/number of nests with at least one hatched egg), and the rate of successful nests (number of nests raising at least one fledgling/ total number of nests). $X^{2}$ tests were then conducted to check whether these rates varied between the two years of study. Linear regressions were carried out to assess whether clutch size, brood size and the number of fledglings varied among nests according to laying date (Julian days, day $1=$ January 1 st), nest elevation and nest volume.

Finally, we used a Generalized Linear Mixed Model (GLMM) to investigate how egg volume varied with clutch size (three categories: four-egg clutches, five-egg clutches and six-egg clutches) and laying date (days after March 1st), while accounting for clutch identity as a random factor. All statistical tests and analyses were carried out using Statistica 12 software (StatSoft Inc 2013).

\section{Results}

\section{Nesting sites}

In 2017 we recorded 119 nests: 13 (11\%) active nest and 106 old unoccupied nests. One breeding pair has laid two clutches (initial and replacement) in two different nests. In 2018, we recorded 20 (15\%) active nests with no replacement clutch. Among these 20 nests we distinguished 4 (20\%) restored old nests, 3 (15\%) reused nests (from active nests in 2017) and 13 (65\%) new built nests. Thus the total number of nests recorded in the study area in 2018 was 132, showing an increase of $11 \%$ from 2017 to 2018 .

All nests were located in the uncultivated part of the study site and none were found in fruit trees. Nests were mainly built in Searsia tripartita shrubs (121 nests; 91.6\%), which is the most available nesting support in the area (76.5\% of nesting supports), corresponding to an Ivlev's index value close to zero and suggesting a random use of this shrub species (Fig. 2). Remaining nests were located in Ziziphus lotus (4 nests), Olea oleaster (3 nests), Lycium europaeum (2 nests), Acacia cyclops (1 nest) and Acacia horrida (1 nest). Together, these plant species accounted for $9.6 \%$ of potential nesting sites and supported $8.3 \%$ of magpie nests. By contrast, no nest was built in Periploca angustifolia, which is the second

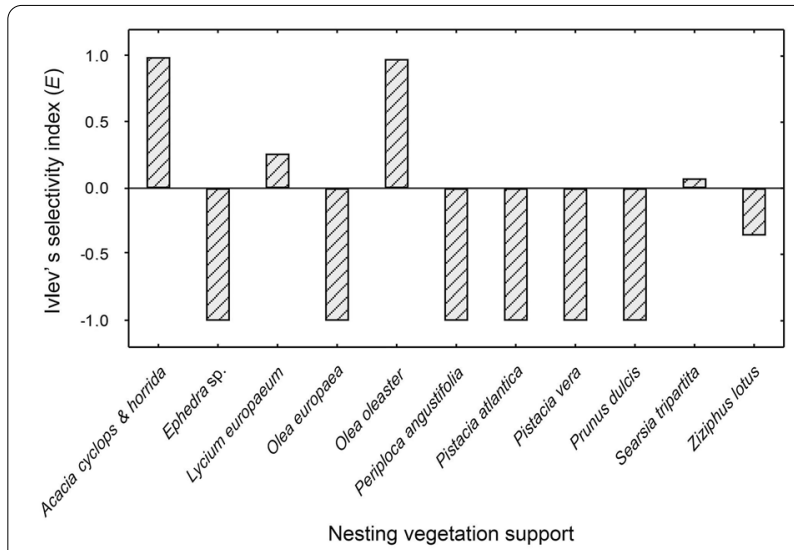

Fig. 2 Ivlev's electivity index values corresponding to each selected nesting vegetal support species by Maghreb Magpie breeding pairs: negative values indicating avoidance, positive values suggesting active selection, and values close to zero indicating random use

most abundant shrub species in the study area (10.5\% of potential nesting vegetation). This gives a negative Ivlev's index value and indicates avoidance of this shrub species (Fig. 2).

Mean height and diameter of nesting shrubs $( \pm \mathrm{SE})$ were $2.87 \pm 0.43 \mathrm{~m}$ (range $2.29-3.90 \mathrm{~m}$ ) and $4.19 \pm 1.17 \mathrm{~m}$ (range $2.50-6.80 \mathrm{~m}$ ) respectively. Nest volume varied between 0.08 and $0.52 \mathrm{~m}^{3}$ and averaged $0.25 \pm 0.04 \mathrm{~m}^{3}$. Nest elevation ranged from 1.10 to $2.09 \mathrm{~m}$, and averaged $1.54 \pm 0.26 \mathrm{~m}$. The height of the nest in the shrub was significantly higher than the distance from the nest to the shrub top $(Z=3.17, P<0.01)$, showing that nests were built above the middle of the shrubs.

\section{Reproductive parameters}

Egg laying occurred between mid-March and mid-April, with $69 \%$ of nests initiated during the second half of March and 31\% in the first half of April.

The breeding parameters remained consistent between years, except for clutch size which was greater in 2017 than 2018 (Table 1).

Over the two years of study, $44 \%$ of eggs laid in the colony were lost during incubation and $39 \%$ of hatchlings were lost before fledging. The main causes of nest failure were depredation of nestlings by Southern Grey Shrike (Lanius meridionalis) (34\% of losses), Egyptian Cobra (Naja haje) (24\%) and rats (Rattus rattus) (18\%). The depredation of parents by raptors, particularly Blackshouldered Kite (Elanus caeruleus) and nest parasitism by the Great Spotted Cuckoo (Clamator glandarius) also accounted for $6 \%$ and $9 \%$ of losses respectively. However, we were unable to identify the cause of $9 \%$ of failed nests.

$\begin{array}{lrrr}\text { Laying date had no effect on } & \text { clutch } \\ \text { size } & (\beta \pm S E=-0.09 \pm 0.30), \quad \text { brood } & \text { size }\end{array}$


Table 1 Breeding parameters of the Maghreb Magpie (Pica mauritanica) recorded during 2017 and 2018 breeding seasons in Tunisia (Sbikha)

\begin{tabular}{lllll}
\hline Breeding parameter & 2017 & 2018 & Years combined & Test for difference between years \\
\hline Active nests & 13 & 20 & 33 & - \\
Replacement clutches & 1 & 0 & 1 & - \\
Range of clutch size & $4-7$ & $3-6$ & $3-7$ & - \\
Modal clutch & 6 & 4 & 6 & - \\
Total number of eggs laid in the colony & 75 & 90 & 165 & $Z=3.56, P=0.000$ \\
Mean clutch size \pm SE & $5.77 \pm 0.69$ & $4.50 \pm 0.18$ & $5.00 \pm 0.19$ & $X^{2}=0.066, P=0.796$ \\
Egg hatching rate (\%) & $55 \%$ & $57 \%$ & $56 \%$ & $Z=0.99, P=0.321$ \\
Hatching success \pm SE & $3.15 \pm 0.54$ & $2.55 \pm 0.44$ & $2.78 \pm 0.34$ & $Z=0.89, P=0.369$ \\
Fledging success \pm SE & $2.07 \pm 0.48$ & $1.45 \pm 0.38$ & $1.69 \pm 0.30$ & $X^{2}{ }_{1}=0.771, P=0.379$ \\
Nestling survival rate (\%) & $66 \%$ & $57 \%$ & $61 \%$ & $X^{2}=0.260, P=0.609$ \\
Breeding success (\%) & $36 \%$ & $32 \%$ & $34 \%$ & $X^{2}{ }_{1}=0.435, P=0.509$ \\
Nest survival (\%) & $85 \%$ & $75 \%$ & $79 \%$ & $X_{1}^{2}=0.257, P=0.611$ \\
Fledging survival (\%) & $82 \%$ & $73 \%$ & $77 \%$ & $X_{1}^{2}=0.668, P=0.413$ \\
Rate of successful nest (\%) & $69 \%$ & $55 \%$ & $61 \%$ &
\end{tabular}

SE standard error

$(\beta \pm \mathrm{SE}=-0.06 \pm 0.30)$ and the number of fledg- $\beta \pm \mathrm{SE}=-0.06 \pm 0.30$ and $\beta \pm \mathrm{SE}=-0.07 \pm 0.30)$ lings produced $(\beta \pm \mathrm{SE}=-0.40 \pm 0.27)$. Moreo- nor with nest elevation $(\beta \pm \mathrm{SE}=0.26 \pm 0.29$, ver, none of these breeding parameters were related $\beta \pm \mathrm{SE}=-0.39 \pm 0.27$ and $\beta \pm \mathrm{SE}=-0.09 \pm 0.30$ ). to nest volume (respectively: $\beta \pm \mathrm{SE}=0.02 \pm 0.30$, Overall, clutch size was lower than those reported

Table 2 Summary of main breeding parameters recorded in the studied population of Maghreb Magpie (current study) in comparison with those known in Eurasian Magpie populations

\begin{tabular}{|c|c|c|c|c|c|c|c|}
\hline \multirow[t]{2}{*}{ Region } & \multicolumn{2}{|c|}{ Egg dimensions (mm) } & \multirow[t]{2}{*}{ Mean (SD) clutch size } & \multirow{2}{*}{$\begin{array}{l}\text { Hatching success } \\
\text { (hatchlings per eggs } \\
\text { laid) }\end{array}$} & \multirow{2}{*}{$\begin{array}{l}\text { Fledging success } \\
\text { (fledglings per } \\
\text { clutch) }\end{array}$} & \multirow[t]{2}{*}{ Laying date } & \multirow[t]{2}{*}{ Source } \\
\hline & Length & Breadth & & & & & \\
\hline Tunisia & $32.26(2.05)$ & $23.01(3.96)$ & $5.00(1.09)$ & 0.56 & $1.69(1.72)$ & Early March & Present study \\
\hline Spain & 33.10 & 23.30 & 6.35 & - & 1.45 & Early April & Arias de Reyna et al. (1984) \\
\hline Spain & - & - & $6.80(1.14)$ & 0.57 & $1.84(2.28)$ & Mid April & $\begin{array}{l}\text { Ponz and Gil-Delgado } \\
\text { (2004) }\end{array}$ \\
\hline Bulgaria & - & - & $6.38(1.15)$ & 0.47 & $1.57(2.34)$ & Early April & $\begin{array}{l}\text { Antonov and Atanasova } \\
\text { (2003) }\end{array}$ \\
\hline France & - & - & 5.70 & - & - & - & Balanca (1984) \\
\hline Belgium & 34.60 & 23.70 & - & - & - & - & Verheyen (1967) \\
\hline Germany & 33.30 & 23.61 & 6.70 & - & - & - & Hund and Prinzinger (1981) \\
\hline Germany & - & - & - & - & 1.20 & - & Sachteleben et al. (1992) \\
\hline Poland & $33.33(2.43)$ & $22.90(0.68)$ & $6.00(1.09)$ & - & 1.13 & Mid April & Jerzak (1995) \\
\hline Netherlands & $33.97(0.16)$ & $23.94(0.07)$ & $6.23(0.89)$ & 0.54 & $1.67(1.46)$ & Mid April & Walters (1988) \\
\hline Britain & - & - & $6.15(1.09)$ & 0.46 & $1.72(2.13)$ & Mid April & Eden (1985) \\
\hline Britain & - & - & - & - & $0.69-0.94$ & Mid March & Vines (1981) \\
\hline Britain & - & - & $5.60(1.44)$ & 0.46 & 1.67 & Mid April & Tatner (1982) \\
\hline Slovenia & $33.60(2.75)$ & $23.20(0.69)$ & $6.00(0.93)$ & - & - & Mid April & Vogrin (1998) \\
\hline Croatia & $33.43(1.38)$ & $23.35(0.52)$ & $5.91(1.08)$ & - & - & - & Dolenec (2000) \\
\hline Uzbekstan & 35.50 & 24.10 & 6.20 & - & - & - & Abdreimov (1981) \\
\hline Kazakhstan & 34.50 & 25.10 & 6.00 & - & - & - & Smetana (1978) \\
\hline Japan & - & - & $6.19(1.30)$ & 0.62 & 0.73 & Mid March & Eguchi (1995) \\
\hline
\end{tabular}

$S D$ standard deviation 
for Eurasian Magpie populations in temperate areas (Table 2), but values of hatching and fledging success were similar (Table 2).

\section{Relationships of egg volume with clutch size and laying date}

Mean length, breadth and volume of Maghreb Magpie eggs $( \pm \mathrm{SE})$ were $32.26 \pm 2.05 \mathrm{~mm}$ (range: $28.60-$ $35.00 \mathrm{~mm}$ ), $23.01 \pm 0.67 \mathrm{~mm}$ (range: $21.56-24.10 \mathrm{~mm}$ ) and $8.74 \pm 0.94 \mathrm{~cm}^{3}$ (range: $6.80-10.16 \mathrm{~cm}^{3}$ ) respectively. These data showed slight differences with egg volume recorded in the temperate Eurasian Magpie populations (Table 2).

Accounting for clutch identity as a random factor, we found that egg volume decreased with laying date $\left(\beta \pm \mathrm{SE}=-0.52 \pm 0.19, F_{1,31}=7.65, P<0.01\right)$ but was unaffected by clutch size $\left(\beta \pm \mathrm{SE}=0.29 \pm 0.18, F_{2,31}=1.06\right.$, $P=0.362$ ).

\section{Discussion}

To our knowledge, this is the first investigation of the breeding ecology of the Maghreb Magpie. Our main objective was to provide detailed data on the nesting habits and breeding success of this declining relictual population. We obtained new and valuable data describing the nesting habitat use and the breeding performance of the Maghreb Magpie. These results are the first and only provided data related to Maghreb Magpie in Tunisia and entire North African region, which is of great interest for the implementation of a possible monitoring and longterm conservation plan of the endangered Tunisian magpie population.

Our results showed that magpie nests were built on thorny bushes, in particular Searsia tripartita which is the most available nest habitat in the area. Non-thorny shrubs, such as Periploca angustifolia, were not used despite their wide availability. In addition, nests were often built just above the middle of the bushes, which is similar to what has been reported in the Eurasian Magpie in temperate rural environments (e.g. Dolenec 2000; Tucakov and Kucsera 2008). This tendency to place nests in the middle of thorny shrubs might be a defense mechanism to limit the accessibility of mammalian and avian nest predators.

We found that clutch size and nest survival in 2018 were lower than those in 2017. Difference seem to be related to weather condition mainly rainfall. Firstly, winter rainfall (September to February) in 2017 (109 mm) was higher than in 2018 (46 mm). According Rodríguez and Bustamante (2003) nest success rate is influenced positively by rainfall in winter. In fact, winter rainfall may increase food availability during incubation since dry winters will force birds to quit incubation to forage when food abundance is low. Secondly, we found that spring rainfall (March to May) in 2017 (16 mm) was lower than recorded in $2018(34 \mathrm{~mm})$. This is in accordance with Rodríguez and Bustamante (2003) demonstrating that rainfall during the nestling period has a negative effect on nest success rate. Thus, spring rainfall at the time of hatching cause temporal declines in foraging activity (Dawson and Bortolotti 2000; Radford et al. 2001) or in food availability (Avery and Krebs 1984), causing mortality of complete clutches of recently hatched chicks. According Senapathi et al. (2011), spring rainfall affects birds to breed later in the season. Delays in breeding cause reduction of reproductive success as birds get exposed to risks associated with adverse climatic conditions later in the breeding season, which reduce nesting success.

We showed that the depredation of Maghreb Magpie nestlings by Southern Grey Shrike was the main cause of nest failure. This species shared the same breeding habitat with Maghreb Magpie. Contrary to previous reports that state Magpies prey on shrikes nests (Cramp and Perrins 1994; Strnad et al. 2012), we found that shrikes were the most common magpie nest predators. Southern Grey Shrike nests inside thorny bushes showing a great ability to squeeze between thorns. Given the two bird species share the same breeding habitat, we believe shrikes kill the nestlings of neighboring magpie pairs to cause nest abandonment. This appears to be an active defense strategy different from the known behavior of shrikes to prevent predation of their nests by magpies: avoid attacking predators that approach the nest so as not to show its location (Syrová et al. 2016). A more detailed study of the predatory interactions between these two species is warranted.

Our preliminaries results showed that the breeding biology of Maghreb Magpie slightly differs from the Eurasian Magpie by nesting earlier and laying smaller clutches and eggs (Högstedt 1980; Tatner 1982; Arias de Reyna et al. 1984; Redondo and Carranza 1989; Ponz and Gil-Delgado 2004; Birkhead 1991). Differences in laying date may obey to a latitudinal gradient effect on birds breeding phenology (Lack 1947, 1968; Cardillo 2002; Jetz et al. 2008). More data and further analysis are needed to verify this hypothesis. The earlier spring in the latitudes of North Africa in comparison with the temperate zones of Tunisia would explain the early entry into reproduction of the Maghreb Magpie compared to the populations of Eurasian Magpie. According de Neve et al. (2004) food availability directly influences laying date in many species, including the Eurasian Magpie, where food supplementation significantly advanced the onset of laying (Meijer and Drent 1999). 
It is known that egg size of magpies significantly increases in response to food supplementation (Högstedt 1981; Hochachka and Boag 1987; Ramsay and Houston 1997; Meijer and Drent 1999; de Neve and Soler 2002; de Neve et al. 2004) despite the relatively inflexibility within individual female birds showed by Christians (2002). The smaller clutches and eggs recorded in our population in comparison with those known in the Eurasian Magpie in temperate zones may be due to possible food scarcity in our arid study area and/or the shorter days at our latitudes. Unfortunately, we did not assess food availability in our study area to test this hypothesis and to investigate more deeply the possible role of food availability in shaping the reproductive investment of the studied birds.

Egg volume varied significantly with laying date, being larger earlier in the season. This pattern matches the general trend known in birds (Bengtson 1972; Parsons 1972; Newton and Campbell 1975; Hill 1984; Sedinger 1992; Christians 2002). This might be due to poorer quality of late breeders compared to early ones. Indeed, some young and less experienced birds often start breeding later and produce less-quality eggs compared to more experienced birds (Christians 2002; Williams 2012; Verhoeven et al. 2019). Alternatively, deteriorating breeding conditions, notably food availability, as the season progress may also result in decreasing egg volume. These hypotheses were not investigated since no data on monitored breeding pairs ages and food availability seasonal changes were available.

Because the number of eggs laid by a female could be traded-off their sizes, a negative relationship between egg size and clutch size could be expected (Blackburn 1991; de Neve and Soler 2002; Ręk 2010). The opposite trend could also be expected as high-quality females may lay larger clutches of larger eggs compared to lowquality females (de Neve and Soler 2002; de Neve et al. 2004; Lifjeld et al. 2005). Given that no significant relationship between egg volume and clutch size was found, our results did not give support to any of the previous hypotheses.

\section{Conclusion}

In conclusion, we believe that without claiming to have completely filled a lack of information, our study provides the first and only detailed data on the reproductive parameters of the Maghreb Magpie in Tunisia and whole North African region. In addition to their potential importance for a possible large-scale comparative study of the reproductive ecology of the magpie complex, these data could be of great interest for the implementation of a possible monitoring and long-term conservation plan of the endangered Tunisian magpie population. In this context, the results of our study would suggest that the preservation of thornier bushes in protected areas, such as the private farm where the study population currently live, could ensure the increase of population size by providing it with more suitable and safe nesting habitat. This would require a short and medium-term conservation program, involving the responsible Tunisian authorities (i.e. general directorate of forests) but also local environmental NGOs, and aiming at sensitizing local farmers and helping them to dedicate parts of their lands to thorny bush plantations.

\section{Acknowledgements \\ Our sincere thanks go to Mr Abdelaziz Mchala, the owner of the farm where the study was carried out, who allowed us free access to the site and for his permanent support for biodiversity. We also express our deep gratitude to Haifa Ouni who contributed to field mission in 2017. We also thank Zakher Bouragaoui for his contribution in paper finalization.}

\section{Authors' contributions}

AN and RO conducted the field work and collected all data. AN statistically analyzed data. SN and SS contributed to results interpretation. AN and SS were a major contributor in writing the manuscript. All authors read and approved the final manuscript.

\section{Funding}

Not applicable.

Availability of data and materials

Not applicable.

\section{Declarations}

Ethics approval and consent to participate

Not applicable.

\section{Consent for publication}

Not applicable.

\section{Competing interests}

The authors declare that they have no competing interests.

\section{Author details}

${ }^{1}$ Department of Biology, Faculty of Sciences of Tunis, University of Tunis El Manar, El Manar II, 2092 Tunis, Tunisia. ${ }^{2}$ Tunisia Wild life Conservation Society, Bejaoua, Sidi Thabit Tunis, Tunisia. ${ }^{3}$ Research Unit "Ecology of Terrestrial Fauna" (UR17ES44), Faculty of Sciences, University of Gabes, Zrig, 6072 Gabes, Tunisia.

Received: 11 September 2020 Accepted: 18 March 2021

Published online: 26 March 2021

\section{References}

Abdreimov T. Birds of deserts and lowlands of Amu Daria. Tashkent: Pub Fan Uzbetskoy SRR Tashkent; 1981

Antonov A, Atanasova D. Small-scale differences in the breeding ecology of urban and rural Magpies Pica pica. Ornis Fennica. 2003;80:21-30.

Arias de Reyna L, Recuerda P, Corvillo M, Cruz A. Reproduccion de la urraca (Pica pica) en Sierra Morena (Andalucia). Donana Acta Vertebrata. 1984;11:79-92.

Avery MI, Krebs JR. Temperature and foraging success of Great Tits Parus major hunting for spiders. Ibis. 1984;126:33-8.

Balanca G. Determinism of reproductive success in a magpie population (Pica pica). Gibier et Faune Sauvage. 1984;4:5-27.

Bengtson SA. Reproduction and fluctuations in the size of duck populations at Lake Mývatn. Iceland Oikos. 1972;23:35-58. 
Bergier P, Thévenot M, Qninba A. Oiseaux du Sahara Atlantique Marocain. Paris: Societé d'Etudes Ornithologiques de France; 2017.

Birkhead TR. The magpies: the ecology and behaviour of black-billed and yellow-billed magpies. London:T \& AD Poyser; 1991.

Blackburn TM. An interspecific relationship between egg size and clutch size in birds. Auk. 1991;108:973-7.

Cardillo M. The life-history basis of latitudinal diversity gradients: how do species traits vary from the poles to the equator? J Anim Ecol. 2002;71:79-87.

Christians JK. Avian egg size: variation within species and inflexibility within individuals. Biol Rev. 2002;77:1-26.

Cramp S, Perrins CM. The birds of the western Palearctic, vol. VIII. Crows to finches. Oxford: Oxford University Press; 1994.

Dawson RD, Bortolotti GR. Reproductive success of American Kestrels: the role of prey abundance and weather. Condor. 2000;102:814-22.

de Neve L, Soler JJ. Nest-building activity and laying date influence female reproductive investment in magpies: an experimental study. Anim Behav. 2002;63:975-80.

de Neve L, Soler JJ, Soler M, Pérez-Contreras T, Martín-Vivaldi M, Martínez JG. Effects of a food supplementation experiment on reproductive investment and a post-mating sexually selected trait in magpies Pica pica. J Avian Biol. 2004;35:246-51.

del Hoyo J, Elliott A, Sargatal J, Christie D, De Juana E. Handbook of the birds of the world alive. Barcelona: Lynx Edicions; 2018.

Dolenec Z. Breeding density, nest sites, clutch size and egg dimensions of the magpie (Pica pica) in NW Croatia. Nat Croat. 2000;9:107-14.

Ebels E. Trends in systematics-speciation in Pica magpies. Dutch Birding. 2003;25:103-16.

Eden S. The comparative breeding biology of magpies Pica pica in an urban and a rural habitat (Aves: Corvidae). J Zool. 1985;205:325-34.

Eguchi K. Seasonal change in breeding success of the Black-billed Magpie Pica pica sericea. Jap J Ornithol. 1995;44:73-80.

Etchécopar RD, Hue F. Les oiseaux du Nord de I'Afrique de la Mer rouge aux Canaries. Paris: Éditions N. Boubée \& Cie; 1964.

Heim de Balzac H, Mayaud N. Les oiseaux du nord-ouest de l'Afrique. Distribution géographique, écologie, migrations, reproduction. Paris: Lechevalier; 1962.

Hill D. Laying date, clutch size and egg size of the Mallard Anas platyrhynchos and Tufted Duck Aythya fuligula. Ibis. 1984;126:484-95.

Hochachka WM, Boag DA. Food shortage for breeding black-billed magpies (Pica pica): an experiment using supplemental food. Can J Zool. 1987;65:1270-4.

Högstedt G. Evolution of clutch size in birds: adaptive variation in relation to territory quality. Science. 1980;210:1148-50.

Högstedt G. Effect of additional food on reproductive success in the magpie (Pica pica). The J Anim Ecol. 1981;50:219-29.

Hoyt DF. Practical methods of estimating volume and fresh weight of bird eggs. Auk. 1979;96:73-7.

Hund K, Prinzinger R. Notizen zur Brutbiologie der Elster Pica pica, Rabenkrähe Corvus corone corone und Dohle Corvus monedulain in Wurttemberg. Ökol Vögel. 1981;3:261-5.

Isenmann P, Moali A. Oiseaux d'Algérie-Birds of Algeria. Paris: Société d'Études Ornithologiques de France; 2000.

Isenmann P, Gaultier T, El Hili A, Azafzah H, Dlensi H, Smart M. Oiseux de Tunisie-Birds of Tunisia. Paris: Société d'Études Ornithologiques de France; 2005.

Ivlev VS. Experimental ecology of the feeding of fishes. New Haven: Yale University Press; 1961.

Jerzak L. Breeding ecology of an urban Magpie Pica pica population in Zielona Góra (SW Poland). Acta Orn. 1995;29:123-33.

Jetz W, Sekercioglu CH, Böhning-Gaese K. The worldwide variation in avian clutch size across species and space. PLoS Biol. 2008;6:e303.

Klug PE, Jackrel SL, With KA. Linking snake habitat use to nest predation risk in grassland birds: the dangers of shrub cover. Oecologia. 2010;162:803-13.

Kryukov AP, Spiridonova LN, Mori S, Arkhipov VY, Red'kin YA, Goroshko OA, et al. Deep phylogeographic breaks in magpie Pica pica across the Holarctic: concordance with bioacoustics and phenotypes. Zoolog sci. 2017;34:185-200.

Lack D. The significance of clutch-size. Ibis. 1947;89:302-52.

Lack D. Ecological adaptations for breeding in birds. London: Methuen \& CO Ltd; 1968.
Lavauden L. Voyage de M Guy Babault en Tunisie. Paris: Résultats Scientifiques (Oiseaux); 1924

Lifield J, Johnsen A, Petitguyot T. Egg-size variation in the bluethroat (Luscinia s. svecica): constraints and adaptation. J Ornithol. 2005;146:249-56.

Meijer T, Drent R. Re-examination of the capital and income dichotomy in breeding birds. Ibis. 1999;141:399-414.

Mougou R, Mansour M, Iglesias A, Chebbi RZ, Battaglini A. Climate change and agricultural vulnerability: a case study of rain-fed wheat in Kairouan. Central Tunisia Region Environ Change. 2011;11:137-42.

Nefla A, Ouni R, Petralia A, Nouira S. Pica mauritanica: una specie a rischio. Grifone. 2020;153:9.

Newton I, Campbell C. Breeding of ducks at Loch Leven. Kinross Wildfowl. 1975;26:83-102.

Ouni H. Ecologie d'une population de la pie du Maghreb (Pica mauritanica, Oiseau Corvidae), espèce relictuelle en Tunisie. Master's thesis. Tunis: Faculty of Sciences of Tunis; 2018.

Ouni R, Ouni H, Nouira S. Premières nidifications du Coucou Geai Clamator glandarius parasite de la Pie d'Afrique du Nord Pica mauritanica. Alauda. 2018;86:62-4.

Parsons J. Egg size, laying date and incubation period in the Herring Gull. Ibis. 1972;114:536-41.

Pietz PJ, Granfors DA. Identifying predators and fates of grassland passerine nests using miniature video cameras. J Wildlife Manage. 2000;64:71-87.

Ponz A, Gil-Delgado J. Breeding biology of Magpie Pica pica in a montane area of Aragon. Ardeola. 2004;51:411-23.

Radford AN, McCleery RH, Woodburn RJW, Morecroft MDM. Activity patterns of parent Great Tits Parus major feeding their young during rainfall. Bird Study. 2001;48:214-20.

Ramsay SL, Houston DC. Nutritional constraints on egg production in the blue tit: a supplementary feeding study. J Anim Ecol. 1997;66:649-57.

Redondo T, Carranza J. Offspring reproductive value and nest defense in the magpie (Pica pica). Behav Ecol Sociobiol. 1989;25:369-78.

Ręk P. Testing the relationship between clutch size and brood size in the Coot (Fulica atra). J Ornithol. 2010;151:163.

Rodríguez C, Bustamante J. The effect of weather on lesser kestrel breeding success: can climate change explain historical population declines? J Anim Ecol. 2003;72:793-810.

Sachteleben J, Blick T, Geyer A, Kröber T, Pönisch S. Bruterfolg, Siedlungsdichte und Raumnutzung der Elster (Pica pica) in unterschiedlichen Habitaten. J für Ornithol. 1992;133:389-402.

Sedinger JS, et al. Ecology of prefledging waterfowl. In: Batt BDJ, Afton AD, Anderson MG, Ankney CD, Johnson DH, Kadlec JA, et al., editors. Ecology and management of breeding waterfowl. Minneapolis: University of Minnesota Press; 1992. p. 109-27.

Senapathi D, Nicoll MAC, Teplitsky C, Jones CG, Norris K. Climate change and the risks associated with delayed breeding in a tropical wild bird population. P Roy Soc B-Biol Sci. 2011;278:3184-90.

Smetana NM. The ecology of the Magpie in incubation and brooding periods in Naourzum reseriation (Northern Kazakhstari). Biologia ptic v Kazakhstanie Alma-Ata. 1978;38:20-8.

Soler JJ, Soler M, Møller AP, Martínez JG. Does the great spotted cuckoo choose magpie hosts according to their parenting ability? Behav Ecol Sociobiol. 1995;36:201-6.

Soler JJ, de Neve L, Martínez JG, Soler M. Nest size affects clutch size and the start of incubation in magpies: an experimental study. Behav Ecol. 2001;12:301-7.

Song G, Zhang R, Alström P, Irestedt M, Cai T, Qu Y, et al. Complete taxon sampling of the avian genus Pica (magpies) reveals ancient relictual populations and synchronous Late-Pleistocene demographic expansion across the Northern Hemisphere. J Avian Biol. 2018;49:e01612.

StatSoft Inc. Electronic statistics textbook. Tulsa: StatSoft; 2013. http://www. statsoft.com/textbook.

Strnad M, Němec M, Veselý P, Fuchs R. Red-backed Shrikes (Lanius collurio) adjust the mobbing intensity, but not mobbing frequency, by assessing the potential threat to themselves from different predators. Ornis Fennica. 2012;89:206-15.

Syrová M, Němec M, Veselý P, Landová E, Fuchs R. Facing a clever predator demands clever responses_-Red-backed shrikes (Lanius collurio) vs. Eurasian Magpies (Pica pica). PLoS ONE. 2016;1 1:e0159432.

Tatner P. The breeding biology of magpies Pica pica in an urban environment. J Zool. 1982;197:559-81. 
Thévenot M, Vernon R, Bergier P. The birds of Morocco: an annotated checklist. Tring: British Ornithologists' Union \& British Ornithologists' Club; 2003.

Tucakov M, Kucsera I. Nest site selection and density of Magpie Pica pica in Novi Sad (Serbia). Vogelwelt. 2008;129:97-101.

Verheyen R. Oologia Belgica: (Planches). Brussels: Institut Royal des Sciences Naturelles de Belgique; 1967.

Verhoeven MA, Loonstra AJ, McBride AD, Tinbergen JM, Kentie R, Hooijmeijer JC, et al. Variation in egg size of Black-tailed Godwits. Ardea. 2019;107:291-302.

Verhulst S, Nilsson JA. The timing of birds' breeding seasons: a review of experiments that manipulated timing of breeding. Philos Trans Roy Soc B Biol Sci. 2008;363:399-410.
Vines G. A socio-ecology of magpies Pica pica. Ibis. 1981;123:190-202. Vogrin M. Density, nest site and breeding success of a rural population of the Magpie (Pica pica) in NE Slovenia. Vogelwarte. 1998;39:293-7.

Wang Y, Chen S, Jiang P, Ding P. Black-billed Magpies (Pica pica) adjust nest characteristics to adapt to urbanization in Hangzhou, China. Can J Zool. 2008;86:676-84.

Williams TD. Physiological adaptations for breeding in birds. Princeton: Princeton University Press; 2012.

Walters J. Breeding data of the Magpie Pica pica. Limosa. 1988;61:33-40.
Ready to submit your research? Choose BMC and benefit from:

- fast, convenient online submission

- thorough peer review by experienced researchers in your field

- rapid publication on acceptance

- support for research data, including large and complex data types

- gold Open Access which fosters wider collaboration and increased citations

- maximum visibility for your research: over $100 \mathrm{M}$ website views per year

At BMC, research is always in progress.

Learn more biomedcentral.com/submissions 